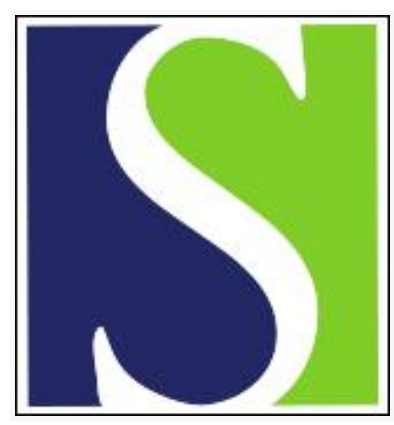

Scand J Work Environ Health 1981;7(4):311-312

https://doi.org/10.5271/sjweh.2542

Issue date: Dec 1981

Sources of variation in fluorometry of zinc protoporphyrin in blood.

by Granjean P, Lintrup J

Key terms: blood; fluorometry; letter to the editor; variation; zinc protoporphyrin

This article in PubMed: www.ncbi.nlm.nih.gov/pubmed/7347917

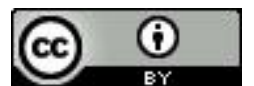




\section{Sources of variation in fluorometry of zinc protoporphyrin in blood}

A few years ago, scientists at the Bell Laboratories in New Jersey, USA, constructed a front-face fluorometer for the rapid determination of erythrocyte zinc protoporphyrin (ZPP) in fresh capillary blood (1). This instrument, called the hematofluorometer, is currently marketed by at least two or three manufacturers and is to an increasing degree used in screening for lead poisoning (4).

Each instrument has excellent precision, but the correlation between the performance of different instruments shows some scattering (3). In a Danish quality-control program for ZPP measurements, similar variations were recorded. The hematofluorometer result is sensitive to the presence in the blood sample of substances that absorb or fluoresce at the wavelengths of the primary and secondary filters of the instrument: 423 and $594 \mathrm{~nm}$, respectively. Both total bilirubin (free and albumin-bound) and free protoporphyrin have been shown to cause such interference $(2,5,6)$. The characteristics of the photomultiplier tubes and the filter band pass may be subject to some variability, and the sensitivity to interference could therefore vary.

We have examined the performance of three hematofluorometers of two different makes: model ZPP meter, Aviv Associates, PO Box 994, Lakewood, NJ 08701, USA; and $\mathrm{ZnP}$ model 4000, Environmental Sciences Associates, Bedford, MA 01730, USA. Total protoporphyrin was determined after extraction, as previously described (5).

In erythropoietic protoporphyria (EPP), most of the protoporphyrin in the blood is free; very little, if any, is bound to zinc. ZPP readings are increased because of the free-protoporphyrin fluorescence. The three hematofluorometers showed a large variability (table 1).

The presence of bilirubin may also affect the hematofluorometer read-out. We centrifuged two fresh venous-blood samples and exchanged the plasma with a solution of freeze-dried plasma with a bilirubin concentration of $70 \mu \mathrm{mol} / \mathrm{l}$, ie, about threefold the upper reference limit. The bilirubin caused the ZPP readings 
Table 1. Results obtained when erythrocyte zinc protoporphyrin was measured with three different instruments. (EPP $=$ erythropoietic protoporphyria).

\begin{tabular}{lccccc}
\hline \multicolumn{2}{c}{ EPP patients } & $\begin{array}{c}\text { Total } \\
\text { protoporphyrin } \\
(\mu \mathrm{mol} / \mathrm{mol} \mathrm{Hb})\end{array}$ & Aviv I & Aviv II & $\begin{array}{c}\text { Hematofluorometer results } \\
(\mu \mathrm{mol} / \mathrm{mol} \mathrm{Hb})\end{array}$ \\
\hline Sex & Age (a) & 1,780 & 95 & 150 & 430 \\
Male & 28 & 2,610 & 80 & 140 & 480 \\
Female & 37 & 2,610 & 110 & 190 & 440 \\
Female & 43 & 1,220 & 85 & 120 & 230 \\
Female & 75 & & &
\end{tabular}

with each instrument to be about twice as high. From the figures presented by Buhrman et al (2), we estimate that the ZPP result with their ESA hematofluorometer would have been even higher.

Intercalibration studies clearly indicate that results with each hematofluorometer need to be compared with those attained with the reference extraction technique (3, $5,7)$. A close correlation should be achieved. We also recommend that each instrument be examined with regard to interference from bilirubin and free protoporphyrin.

Finally, a note on units of measurement. The hematofluorometer measures the ratio between the light absorption by oxyhemoglobin and the fluorescence of zinc protoporphyrin. The result is therefore a ratio between the two substances, which is the most appropriately expressed in molar units, eg, micromole per mole of hemoglobin (iron). Results given in this unit should be divided by 25 to obtain results expressed as mass ratio in micrograms per gram (which is the unit sometimes used, although a molar ratio is more appropriate in this situation).

\section{References}

1. Blumberg WE, Eisinger J, Lamola AA. The hematofluorometer. Clin chem 23 (1977) $270-274$
2. Buhrmann E, Mentzer WC, Lubin BH. The influence of plasma bilirubin on zinc protoporphyrin measurement by hematofluorometer. J lab clin med 91 (1978) 710-716.

3. D'Andrea F, Alessio L, Apostoli P. Determinazione della zincoprotoporfirina eritrocitaria, problemi metodologici. In: Atti del XLII Congresso della Societá Italiana di Medicina del Lavoro e Igiene Industriale, Trieste, 2, 1980 pp 259-268.

4. Grandjean P. Lead exposure in Denmark, screening with the haematofluorometer. $\mathrm{Br}$ $j$ ind med 36 (1979) 52-58.

5. Grandjean P, Lintrup J. Erythrocyte-Znprotoporphyrin as an indicator of lead exposure. Scand $j$ clin lab invest 38 (1978) $669-675$.

6. Lamola AA, Eisinger J, Blumberg WE. Bilirubin sensitivity of zinc protoporphyrin hematofluorometers. J lab clin med 93 (1979) 345-348.

7. Peter F, Growcock G, Strunc G. Fluorometric determination of erythrocyte protoporphyrin in blood, a comparison between direct (hematofluorometric) and indirect (extraction) methods. Clin chem 24 (1978) $1515-1516$

Philippe Grandjean, MD, ${ }^{1}$ Jens Lintrup, $\mathrm{MD}^{2}$

1 Danish National Institute of Occupational Health, DK-2900 Hellerup, Denmark.

2 Department of Clinical Chemistry, Finsen Institute, DK-2100 Copenhagen $\varnothing$, Denmark. 